\title{
TMPRSS2-ERG fusions confer efficacy of enzalutamide in an in vivo bone tumor growth model
}

\author{
Louie Semaan ${ }^{1}$, Navneet Mander ${ }^{1}$, Michael L. Cher ${ }^{1,2,3}$ and Sreenivasa R. Chinni ${ }^{1,2,3^{*}}$ (D)
}

\begin{abstract}
Background: Castrate Resistant Prostate Cancer (CRPC) is an advanced disease resistant to systemic traditional medical or surgical castration, and resistance is primarily attributed to reactivation of AR through multiple mechanisms. TMPRSS2-ERG fusions have been shown to regulate AR signaling, interfere with pro-differentiation functions, and mediate oncogenic signaling. We have recently shown that ERG regulates intra-tumoral androgen synthesis and thereby facilitates AR function in prostate cancer cells. We hypothesize that enzalutamide treatment will be more effective in cells/tumors with TMPRSS2-ERG translocations because these tumors have increased AR signaling.

Methods: ERG knockdown was performed with VCaP cells using lentiviral infections to generate VCaP ERGshRNA cells and control VCaP scr cells with scrambled shRNA. Cell-growth analysis was performed to determine the effect of enzalutamide. Reverse transcription, quantitative real-time PCR (RT-qPCR) was used to determine the expression of AR responsive genes. Luciferase tagged $\mathrm{VCaP}$ scr and shRNA infected cells were used in an intra-tibial animal model for bone tumor growth analysis and enzalutamide treatment used to inhibit AR signaling in bone tumors. Western blotting analyzed VCaP bone tumor samples for ERG, AR, AKR1C3 and HSD3B1 and HSD3B2 expression.

Results: Enzalutamide inhibited the growth of VCaP scr cells more effectively than shERG cells. Analysis of AR responsive genes shows that Enzalutamide treatment at 5 micromolar concentration inhibited by $85-90 \%$ in VCaP $\mathrm{Scr}$ cells whereas these genes were inhibited to a lesser extent in VCaP shERG cells. Enzalutamide treatment resulted in severe growth inhibition in VCaP scr shRNA cells compared to VCaP shERG cells. In bone tumor growth experiment, VCaP ERG shRNA cells grew at slower than VCaP scr shRNA cells. Androgen biosynthetic enzyme expression is lower VCaP shERG bone tumors compared to VCaP scr shRNA bone tumors and enzalutamide inhibited the enzyme expression in both types of tumors.
\end{abstract}

Conclusions: These data suggest that ERG transcription factor regulates androgen biosynthetic enzyme expression that enzalutamide treatment is more effective against VCaP bone tumors with an intact ERG expression, and that knocking down ERG in VCaP cells leads to a lesser response to enzalutamide therapy. Thus, ERG expression status in tumors could help stratify patients for enzalutamide therapy.

Keywords: TMPRSS2-ERG, Castrate resistant prostate cancer, Enzalutamide, Bone tumors, Androgen receptor, Androgen biosynthetic enzymes, AKR1C3, HSD3B1 and HSD3B2

\footnotetext{
* Correspondence: schinni@med.wayne.edu

$\mathrm{NIH}-\mathrm{NCl}$ Grant CA151557 and Astellas and Medivation

'Department of Urology, Wayne State University School of Medicine, 9245

Scott Hall, 540 E. Canfield Avenue, Detroit, MI 48201, USA

${ }^{2}$ Department of Pathology, Wayne State University School of Medicine,

Detroit, Ml 48201, USA

Full list of author information is available at the end of the article
}

(c) The Author(s). 2019 Open Access This article is distributed under the terms of the Creative Commons Attribution 4.0 International License (http://creativecommons.org/licenses/by/4.0/), which permits unrestricted use, distribution, and reproduction in any medium, provided you give appropriate credit to the original author(s) and the source, provide a link to the Creative Commons license, and indicate if changes were made. The Creative Commons Public Domain Dedication waiver (http://creativecommons.org/publicdomain/zero/1.0/) applies to the data made available in this article, unless otherwise stated. 


\section{Background}

Androgen deprivation therapies in prostate cancer patients are effective in reducing systemic levels of androgens. However, studies demonstrate that intratumoral androgens do not change significantly, and those levels are sufficient to activate AR growth signaling pathways [1-4], suggesting that, in a castrate environment, tumors have the capability to make local androgens. Subsequent studies showed that in CRPC, tumor tissues exhibit enhanced levels of androgen biosynthetic enzyme expression $[5,6]$. Production of tumoral androgens in the castrate environment can be enhanced from adrenal precursors such as dehydroepiandrosterone (DHEA) and androstenediol, and directly from cholesterol. Several studies suggest that, downstream of the CYP17 gene in the androgen pathway, there could be a viable alternate target for intratumoral androgen production [7-10]. How expression of these androgen biosynthetic enzymes is regulated in CRPC remains to be investigated. We showed for the first time that ERG transcription factor regulates androgen biosynthesis and subsequent AR activation in prostate cancer cells [11]. ERG transcription factor is expressed in PC tumors from TMPRSS2-ERG fusion gene and the presence of this fusion is highly prevalent in PC patients, including CRPC. The presence of TMPRSS2-ERG fusions is associated with high grade disease [12], and different subsets of rearrangements including $2+$ Edel, T2-E4, and the presence of a $72 \mathrm{bp}$ insert in the ERG gene are associated with aggressive disease characteristics [13-15]. ERG has been shown to bind AR responsive gene promoters throughout the genome and regulate AR signaling, interfere with prodifferentiation functions, and mediate oncogenic signaling [16]. Also cooperation between AR and ERG drives invasive adenocarcinoma [17] even in the castrate environment [18]. However, mechanisms underlying the cooperation of AR and ERG with each other in a low androgen environment remain unknown. In a low androgen CRPC state, AR reprograms gene expression for enhanced cell cycle progression [19], which is distinct from the prodifferentiation function. ERG fusion status is also related to abiraterone acetate therapy responsiveness, where fusion positive patients responded well to therapy, suggesting a role of the fusion gene in androgen production [20]. Our previous study supports this notion and defined a feed forward loop consisting of TMPRSS2-ERG fusions, androgen biosynthetic enzymes and AR activation operating in prostate cancer cells which drives intracellular DHT production. In this study, we tested the biological significance of ERG induced androgen production on bone tumor growth and targeting AR signaling with enzalutamide.

Bone metastases are highly prevalent occurrences in both hormone-naïve and CRPC patients. Androgen receptor expression is prevalent in bone metastases where both full length [21] and shorter AR variants [22, 23] are expressed in metastasized prostate tumor cells. Nuclear AR staining in bone metastases associate with poor outcome in patients, suggesting AR signaling in promoting bone tumor growth [21]. At a cellular level, AR expression and signaling has been active in mature osteoblasts, osteocytes, and stromal cells [24-26] that maintain normal bone function. In support of this argument, a clinical trial with abiraterone acetate showed that treated patients have lower testosterone levels in bone marrow tumor biopsies [27], suggesting the prevalence of androgen production in bone metastatic sites.

Our previous study demonstrates that AR/ERG/Androgen biosynthetic enzymes form a feed forward loop in TMPRSS2-ERG fusion positive cells for androgen production and growth [11]. This study is focused on determining the impact of breaking this feedforward loop on bone tumor growth. We utilized ERG knockdown approach in TMPRSS2-ERG positive cells and targeting the AR function with enzalutamide for bone tumor growth. We show that ERG positive cells/tumors are highly responsive to enzaluatimde treatment. AR responsive genes in CRPC state are inhibited by enzaluatamide treatment in ERG positive cells. Androgen biosynthetic enzyme gene expression is inhibited in ERG knockdown tumors andenzalutamide significantly inhibited androgen biosynthetic enzyme expression in ERG positive tumors likely through abrogating the feedback back mechanism involving AR/ERG/androgen biosynthetic enzyme expression [11]. This data supports the notion that TMPRSS2-ERG fusion positive tumors are better responders to enzalutamide therapy.

\section{Methods}

\section{Cell lines and treatments}

The parental VCaP cell line was obtained from ATCC (Catalogue number CRL-2876) and cultured in DMEM media. Preparation of $\mathrm{VCaP}$ Scrambled shRNA and VCaP shERG RNA cells were described previously [11]. Cell lines were cultured in a humidified incubator with $5 \% \mathrm{CO}_{2}$ at $37^{\circ} \mathrm{C}$. All media were supplemented with 2 $\mathrm{mM}$ glutamine, 100 units $/ \mathrm{mL}$ penicillin, and $100 \mu \mathrm{g} / \mathrm{mL}$ streptomycin (Life Technologies Inc., Carlsbad, CA). VCaP Scrambled shRNA Control and VCaP shERG RNA cells were maintained in ATCC-DMEM media supplemented with $(0.3 \mu \mathrm{g} / \mathrm{mL})$ puromycin. Both cell lines were authenticated with STR analysis (Genomics core at Michigan State University, East Lansing, MI) and shown to have markers respective for each cell line as established by ATCC and also tested for mycoplasma contamination prior to use, with VenorGeM mycoplasma detection kit (Sigma Biochemicals, St. Louis, MO). 


\section{Cell proliferation}

VCaP Scrambled shRNA and VCaP ERG shRNA cells were seeded in a Cell-Bind 96-well, black culture plate at a cell density of 10,000 cells per well in $100 \mu \mathrm{L}$ media supplemented with $10 \mu \mathrm{M}$ of HEPES. Cells were seeded in quadruplicates and incubated for $24 \mathrm{~h}$ (to allow adhesion). The following day cells were treated with 5, 10 and $20 \mu \mathrm{M}$ of enzalutamide. Cells were assessed for growth at the indicated times $(2,3$, and 5 days $)$ by CyQuant NF cell proliferation fluorescence assay kit (Cat\# C35006- Invitrogen Molecular Probes). Growth media and enzalutamide treatment were replenished at day 3 for continued drug effect. Relative fluorescence units were quantified using a fluorescent plate reader.

\section{Gene expression}

VCaP Scrambled shRNA and VCaP ERG shRNA cells were seeded in 6 well plates at a cell density of $5.0 \times 10^{5}$ cells per well. Cells were treated with 5 and $20 \mu \mathrm{M}$ of enzalutamide for 5 days, with media replenished on day 3. On day 5, RNA was extracted using the Trizol (Invitrogen, Carlsbad, CA) method. For RT-qPCR experiments, cDNA was synthesized from total RNA using the iScript cDNA synthesis kit obtained from Bio-Rad (cat.\# 170-8891) with an Eppendorf Mastercycler. For RTqPCR experiments cDNA was amplified with primers and SYBR green from Maxima SYBR Green/ROX qPCR Master Mix (2X) obtained from Thermo Scientific (cat.\# KERK0221) using an Eppendorf Mastercycler Realplex ${ }^{2}$ qPCR machine. Fold change levels among gene expression were quantitated using comparative $\mathrm{Ct}$ method. In this study AR responsive genes related to differentiation such as PSA and TMPRSS2, and CRPC genes, such as, UBE2C, CDK1, CCNA2 and CDC20 were analyzed.

PCR primers are listed in Table 1.

\section{In vivo studies}

For in-vivo studies VCaP Scrambled shRNA Control and VCaP ERG shRNA cells were infected with Luciferase-2 lentiviral particles in order to capture in-vivo bioluminescence images of tumors. Castrated five-week old male C.B.-17 severe combine immunodeficient (SCID) mice (Taconic Farms, Germantown, $\mathrm{NY}$ ) were used in this study. All the procedures including animal housing, surgery, imaging, the methods of anesthesia and euthanasia prior to tumor tissue analysis were performed as per the institutional animal care and use committee approved protocol. For intratibial implantation, $1.0 \times 10^{6}$ cells in a $10 \mu \mathrm{l}$ volume were injected per bone. Animals were imaged periodically to measure bone tumors. Animals with established bone tumors were randomized and treated with a dose of $50 \mathrm{mg} / \mathrm{kg}$ body weight of enzalutamide or placebo control by oral gavage. Luciferase imaging of tumors were performed with Carestream Invivo Xtreme system. At the end of the experiment animals were euthanized with carbon dioxide inhalation method and bone tumors were collected for Western blot analysis and quantifying tumoral androgen levels.

\section{Western blot analysis}

VCaP shscrambled and shERG bone tumor were weighed and supplemented with (100 mg tumor in 900uL RIPA $\left.{ }^{++}\right)$ RIPA buffer (50 mM Tris- $\mathrm{HCl}, \mathrm{pH} 8.0,150 \mathrm{mM} \mathrm{NaCl}$, $0.5 \%$ sodium deoxycholate, $1 \% \mathrm{NP}-40$ ) plus protease (1X complete Mini protease inhibitor cocktail tablets) and phosphatase $(10 \mathrm{mM}$ sodium pyrophosphate, $25 \mathrm{mM} \beta$ glycerophosphate, $25 \mathrm{mM} \mathrm{NaF}, 2 \mathrm{mM} \mathrm{NaVO}$ ) inhibitors $\left(\mathrm{RIPA}^{++}\right)$and homogenized using a Precellys 24 Homogenizer (PEQLAB, Wilmington, DE), mixing endover-end at $4{ }^{\circ} \mathrm{C}$ for 15 min followed by centrifugation at $15,000 \times \mathrm{g}$ for $15 \mathrm{~min}$. Protein concentrations were determined using BCA reagent (Pierce), and 30-40 $\mu$ g protein was analyzed by Western blot analysis. Membranes were blocked with 5\% BSA/TBST and probed with primary antibody in 5\% BSA/TBST. Membranes were probed with HRP-linked secondary antibody in 5\% BSA/TBST. Protein bands were detected using enhanced chemiluminescence substrate and autoradiography film. Primary and secondary antibodies are listed in supplementary table below. Densitometry was performed using ImageJ software (NIH). The details of antibodies used in Western blot analysis were provided in Table 2.

\section{Tumoral androgen quantitation}

For tumoral testosterone measurements, total lipids were extracted from bone tumor using a Sep-pak cartridge

Table 1

\begin{tabular}{lll}
\hline CRPC Genes & Forward $\left(5^{\prime} \rightarrow 3^{\prime}\right)$ & Reverse $\left(5^{\prime} \rightarrow 3^{\prime}\right)$ \\
\hline UBE2C & TGGTCTGCCCTGTATGATGT & AAAAGCTGTGGGTTTITCC \\
CDK1 & CCTAGTACTGCAATTCGGGAAATT & CCTGGAATCCTGCATAAGCAC \\
CCNA2 & CAGAAAACCATTGGTCCCTC & CACTCACTGGCTTITCATCTTC \\
CDC20 & CCTCTGGTCTCCCCATTAC & ATGTGTGACCTTTGAGTTCAG \\
TMPRSS2 & CAGGAGTGTACGGGAATGTGATGGT \\
GAPDH & GTCACCATCTTCCAGGAGCGA & GCCAGTGAGCTTCTGCCCGTCATTTGT \\
\hline
\end{tabular}


Table 2

\begin{tabular}{llll}
\hline Primary Antibody & Vendor & Catalog number & Dilution \\
ERG 1/2/3 & Santa Cruz Biotechnology & sc-28,680 & $1: 5000$ \\
AR (N-20) & Santa Cruz Biotech & sc-816 & $1: 1000$ \\
GAPDH & Santa Cruz Biotech & sc-25,778 & $1: 10000$ \\
AKR1C3 & Sigma Aldrich & A6229 & $1: 1000$ \\
HSD3B1 & Sigma Aldrich & WH0003283M1 & $1: 1000$ \\
HSD3B2 & Sigma Aldrich & SAB1402232 & $1: 1000$ \\
Secondary Antibody & Vendor & Catalog number & Dilution \\
Anti-rabbit lgG, HRP & Cell Signaling Technology & 70745 & $1: 5000$ \\
Anti-mouse lgG, HRP & Cell Signaling Technology & 70765 & $1: 5000$ \\
\hline
\end{tabular}

obtained from Waters Corporation (Milford, MA, WAT023590). Lipid samples were eluted with acetonitrile into HPLC/MS/MS vials obtained from MicroSOLV Technology (Eatontown, NJ, 9512S-0CV vials, 9502S-10C-B tops) and subjected to HPLC/MS/MS analysis at the Wayne State University Lipidomics Core Facility as described previously [11].

\section{Statistical analysis}

Statistical analyses were performed using GraphPad Prism Version 5.0.

\section{Results}

TMPRSS2-ERG fusion positive cell growth is sensitive to enzalutamide exposure

Our previous study showed that ERG factor regulates androgen biosynthesis and that intracellular androgen production activates AR responsive gene expression [11]. Here we tested whether ERG factor could be a better marker for androgen receptor mediated cell growth. We have previously showed that $\mathrm{VCaP}$ cells in culture are known to produce androgens and knockdown ERG with shRNA leads to decrease in androgen production [11]. We generated a pair of isogenic $\mathrm{VCaP}$ cell lines, where we
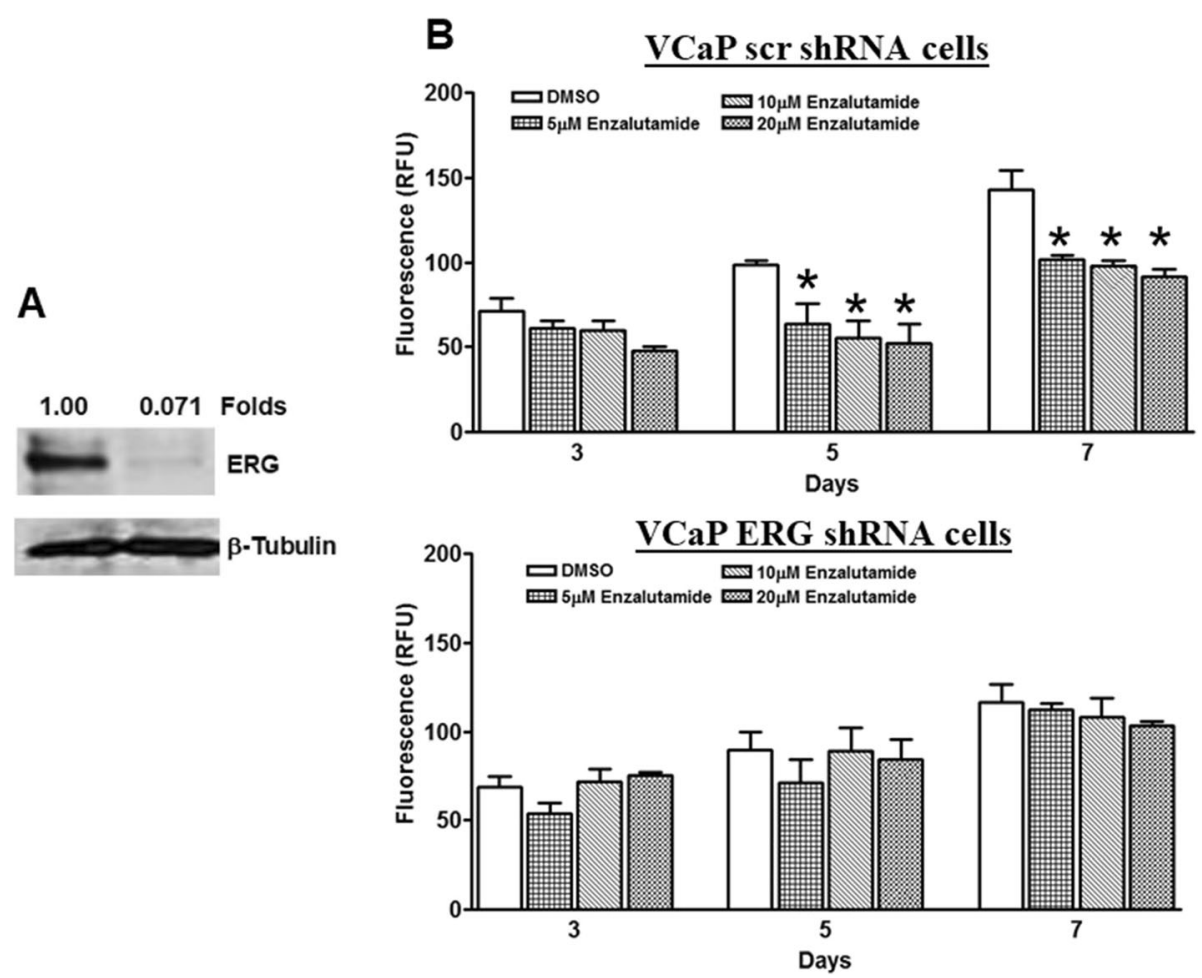

Fig. 1 Enzalutamide inhibits TMPRSS2-ERG fusion positive cancer cell growth. a Western blot analysis of VCaP Scr shRNA and VCaP ERG shRNA cells for ERG and b-tubulin expression. ERG expression was normalized for b-tubulin and fold differences between VCaP Scr shRNA and VCaP ERG shRNA cells were shown. $\mathbf{b}$ Cell growth analysis of VCaP scr shRNA and VCaP ERG shRNA cells treated with 5-20 $\mu \mathrm{M}$ concentrations of enzalutamide for 3,5 and 7 days. * Indicate the $p<0.05$ between groups (DMSO vs. enzalutamide treatment) using student t-test and $n=3$ 
stably infected with ERG shRNA to knock down ERG expression, or with scrambled shRNA as a control cell line with intact ERG expression, Western blot analysis show that ERG factor expression is significantly down regulated in VCaP ERG shRNA cells compared to VCaP scr shRNA cells (Fig. 1a). Treatment with enzalutamide showed that $\mathrm{VCaP}$ scr shRNA cells are sensitive to cell growth inhibition starting from $5 \mu \mathrm{M}$ concentration at day 5 and 7; whereas, ERG knockdown cells did not show cell growth inhibition at these concentration (Fig. 1b). Together these data suggest that ERG expression confer the responsiveness to enzalutamide treatment.

\section{Enzalutamide inhibits AR dependent gene expression in ERG positive cells}

Previous studies defined AR gene signatures specific to the CRPC phase of disease are selectively upregulated M-phase cell cycle genes [19], and expression of these genes in ERG intact and knockdown cells were evaluated. Data showed that CDK1, CCNA2 and CDC20 are downregulated in ERG knockdown cells, whereas UBE2C is upregulated in ERG knockdown cells; similarly, among AR responsive genes, TMPRSS2 is downregulated in ERG knockdown cells and PSA is upregulated in ERG knockdown cells (Fig. 2a). ERG has been shown to regulate several AR responsive genes in PC cells [16] and its knockdown in VCaP cells resulted in upregulation of these genes.
Both VCaP scrambled shRNA (high ERG) and VCaP ERGshRNA (low ERG) cells were exposed to DMSO (as a control) or 5 and $20 \mu \mathrm{M}$ enzalutamide for 5 days. QPCR analysis of AR responsive genes TMPRSS2 and PSA, and CRPC genes UBE2C, CDK1, CCNA2 and CDC20 shows that expression of all these genes was highly downregulated at both concentrations in $\mathrm{VCaP}$ scrambled shRNA (high ERG) cells (Fig. 2b). At $5 \mu \mathrm{M}$ concentration of enzalutamide, $85-95 \%$ of these gene expressions were downregulated and at $20 \mu \mathrm{M}$ concentration these gene expressions were downregulated to the extent of $3 \log$ units in ERG intact cells. However, in VCaP ERG shRNA (low ERG) cells, enzalutamide did not inhibit the TMPRSS2 gene expression at $5 \mu \mathrm{M}$ concentration and all other genes were inhibited to a lower extent compared to ERG intact cells, whereas at $20 \mu \mathrm{M}$ concentration the extent of inhibition in all genes is less than in high ERG cells. Together, these data suggest that AR inhibition through enzalutamide is effective in ERG expressing cells compared to ERG knockdown cells and that the expression of AR responsive genes were highly inhibited in ERG intact cells compared to knockdown cells.

\section{Enzalutamide inhibits bone tumor growth in TMPRSS2- ERG positive cells}

Human bone tumor biopsy studies show that androgen production is present in bone tumors and activation of

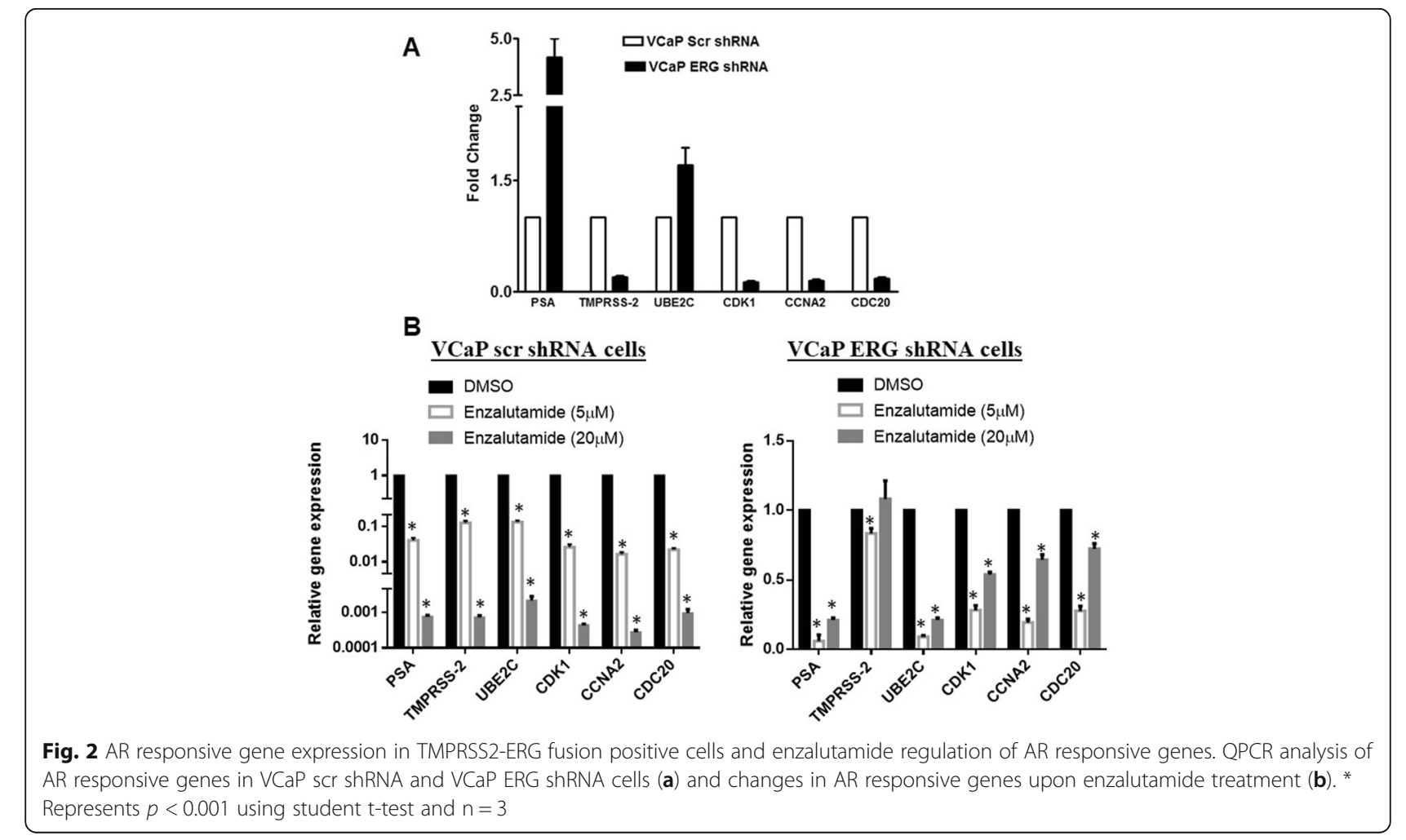


AR signaling contributes to bone tumor growth. To determine how ERG induced androgen synthesis contributes to bone tumor growth and whether ERG activity can be a predictor for anti-androgen therapy responsiveness, we utilized an intratibial bone tumor growth model with VCaP scr and ERG shRNA cells to address these questions. Tumor growth analysis of both cells lines show that VCaP ERG shRNA cells grow more slowly, requiring 4 weeks longer to reach similar growth sizes as assessed by luciferase imaging (Fig. 3a and d). When both tumors reach comparable size, the animals bearing bone tumors were randomized and treated with vehicle (Tween 80) or Enzalutamide by oral gavage. Tumor growth rate is slower in VCaP shERG tumors compared to scr shRNA tumors (Fig. $3 \mathrm{~b}$ and d). Enzalutamide treatment resulted in significant reduction in tumor burden in VCaP scr shRNA group compared to VCaP shERG group (Fig. 3c and d). These data suggest that ERG signaling contributes to bone tumor growth and that AR targeting with enzalutamide significantly inhibits the bone tumor growth presumably through interfering with reduced ERG signaling.
ERG knockdown and enzalutamide therapy inhibited androgen biosynthetic enzyme expression

To determine enzalutamide responsiveness is related to androgen synthesis in bone tumors, we evaluated the expression of key enzymes in androgen synthesis, AKR1C3, HSD3B1 and HSD3B2, in bone tumors. Our previous study demonstrated that ERG factor regulates the expression of these enzymes in prostate cancer cells. Bone tumor analysis shows that ERG knockdown results in diminished expression of AKR1C3 and HSD3B1 in bone tumors (Fig. 4a and b). Enzalutamide treatment also inhibited the expression of all three enzymes in bone tumors. Intratumoral androgens in bone tumors were measured by MS/ MS analysis. Testosterone was detected in vehicle treated tumors, whereas no detectable levels of testosterone were observed with enzalutamide treatment in both groups. This could be due to very small size of tumors which precludes the detectable limit of testosterone through MS analysis. The mean testosterone levels in VCaP scr shRNA tumors were $23.13 \mathrm{ng} / \mathrm{mg}$ protein whereas in $\mathrm{VCaP}$ shERG tumors, they were $8.73 \mathrm{ng} / \mathrm{mg}$ protein, suggesting ERG knockdown inhibited the testosterone production.

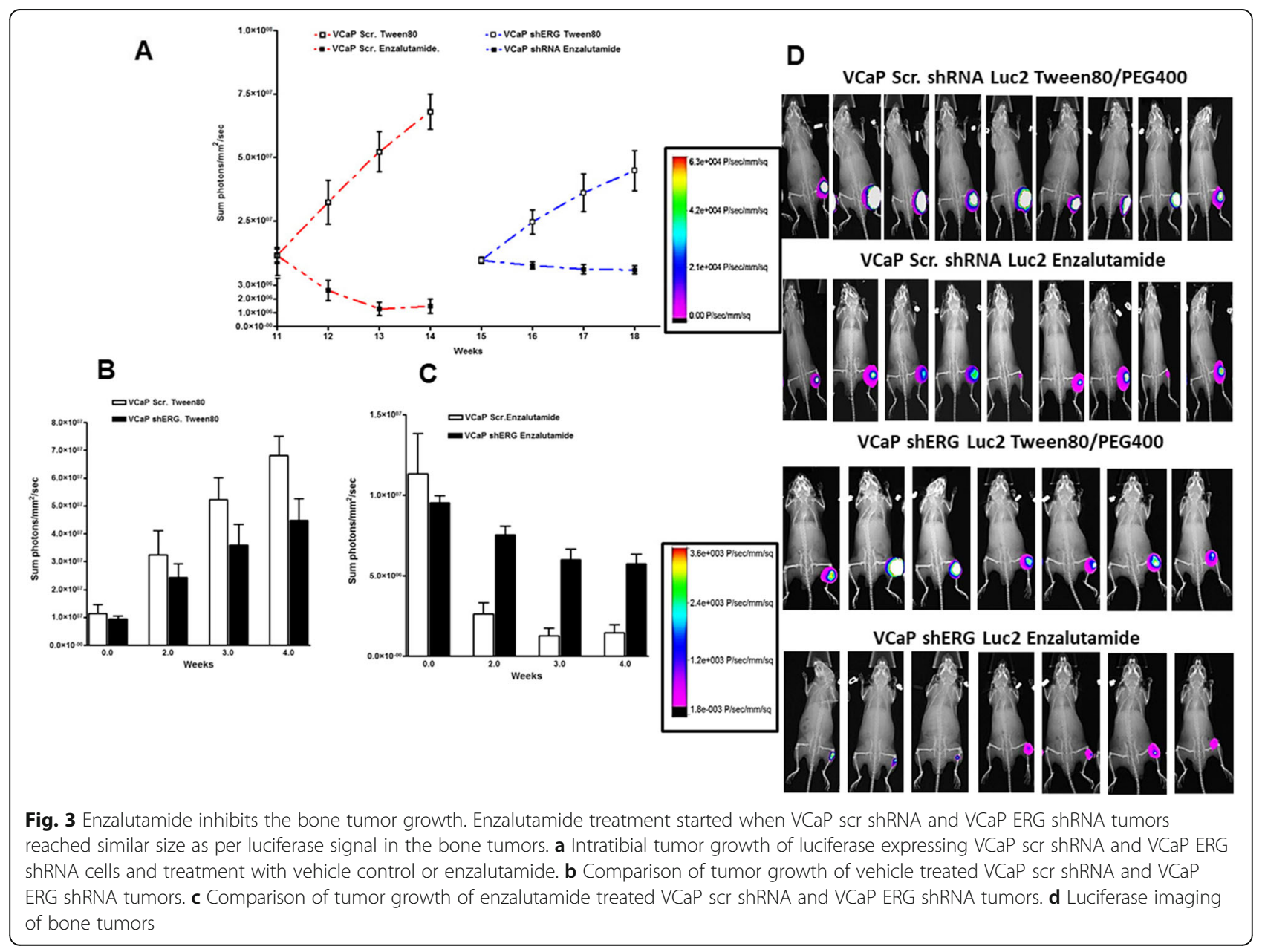


These data suggest that ERG knockdown resulted in the reduced expression of androgen biosynthetic enzyme expression and corresponding lower levels of testosterone in bone tumors. Furthermore, enzalutamide therapy is more effective in ERG positive bone tumor at inhibiting tumor growth compared to ERG knockdown tumors.

\section{Discussion}

Intratumoral androgen synthesis is the mainstay for AR signaling in castration resistance prostate cancer progression. Previous studies support this claim based on overexpression of several androgen biosynthetic enzyme expression coupled with enhanced utilization of adrenal precursors for DHT production in human CRPC tumors. To shed light on the transcriptional regulation of androgen biosynthetic enzymes in tumors, we have previously shown that ERG factor regulates key enzymes in androgen synthesis [11]; thus, TMPRSS2-ERG fusion positive cancer cells producing intracellular androgens are better responders to abiraterone therapy Herein, we extended this concept to in vivo tumor studies. We employed a model system of intact ERG expressing cells (VCaP scr ShRNA) and ERG knockdown cells (VCaP ERG shRNA) cells to test the role of ERG factor in antiandrogen receptor inhibitor (enzalutamide) responsiveness. Our data show that enzalutamide inhibited the growth of VCaP cells expressing TMPRSS2-ERG fusion genes, but when ERG factor was stably knocked down with lentiviral shERG RNA, tumor growth inhibition occurred at lesser extent. Previous study showed a similar enzalutamide dose ( $50 \mathrm{mg} / \mathrm{kg}$ body) inhibited subcutaneous
LNCaP-AR tumors in the CRPC setting [28] suggesting that at this concentration the drug is stable and inducing the tumor regression, which is similar to its efficacy observed in clinical trials with the CRPC patients. Two recent clinical trials evaluated the efficacy of enzalutamide in prior chemotherapy [29] and chemotherapy naïve patients [30] with metastatic prostate cancer. The skeletal related events (SRE) such as number of bone lesions and bone pain was evaluated in these trials as a secondary endpoint. In the chemotherapy trial the enzalutamide significantly prolonged time to develop first SRE and in the chemotherapy naive trial the enzalutamide significantly reduced the risk for developing first SRE in patients.

The data support the notion that ERG regulation of androgen synthesis in cancer cells leads to activation of $\mathrm{AR}$ as shown by AR responsive gene expression and this process is amenable to AR inhibition through enzalutamide for in vivo tumor growth, whereas when ERG factor is downregulated, intracellular androgen synthesis is downregulated and AR is no longer active (as shown by lower AR responsive gene expression), thus, not allowing anti-AR inhibitor enzalutamide to exert to growth inhibition to the extent of inhibition observed with ERG intact tumors (Fig. 5). Among androgen biosynthetic enzymes, we found that HSD3B1/2 and AKR1C3 and are key enzymes regulated by ERG factor in TMPRSS2ERG fusion positive cells [11]. Enzymatic pathways of these two enzymes have been shown to be key determinants of DHT production through androstandione (5 a-dione) pathway, where HSD3B family enzymes catalyzes the irreversible step of converting DHEA to androstendione; and

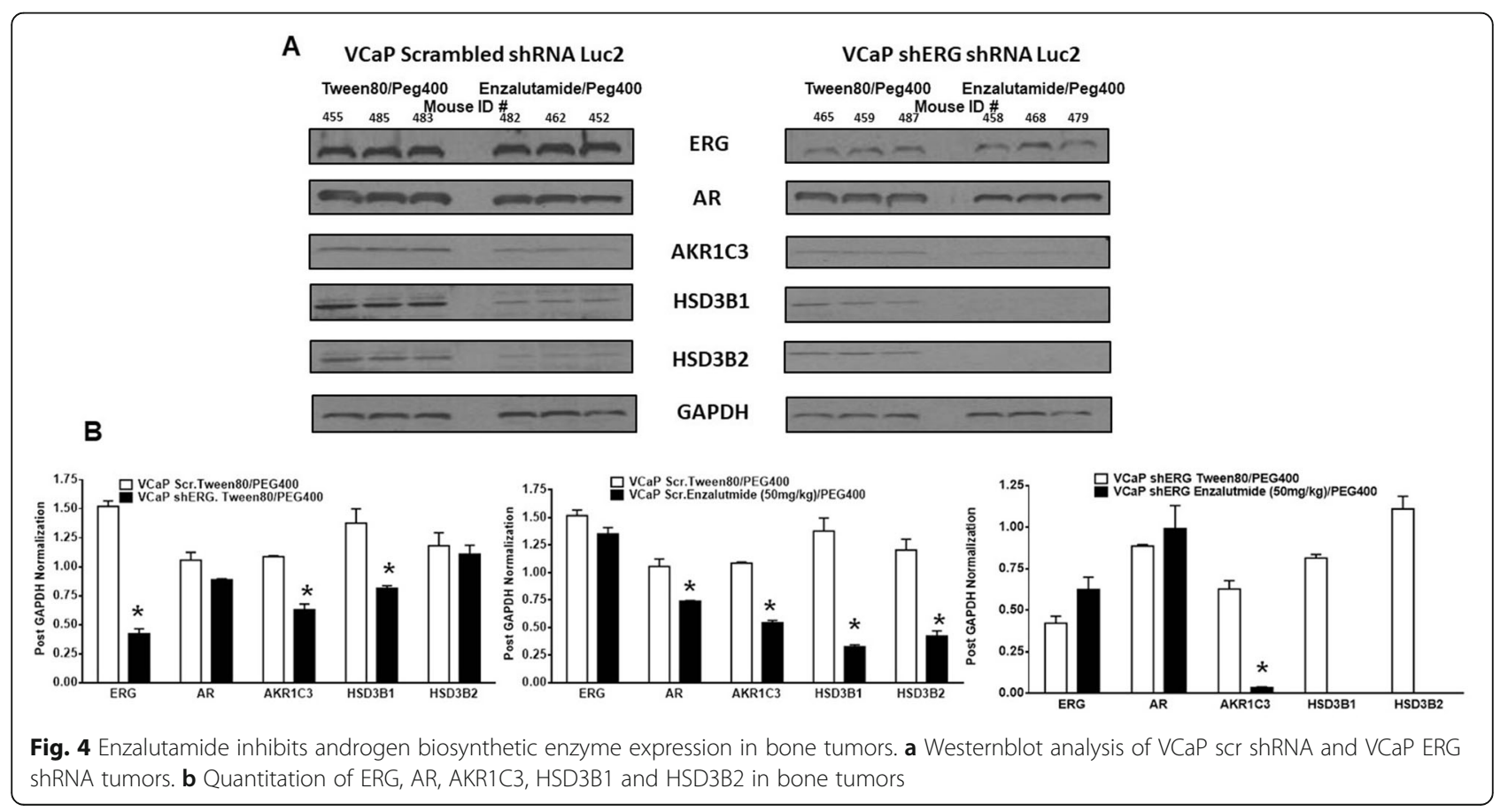




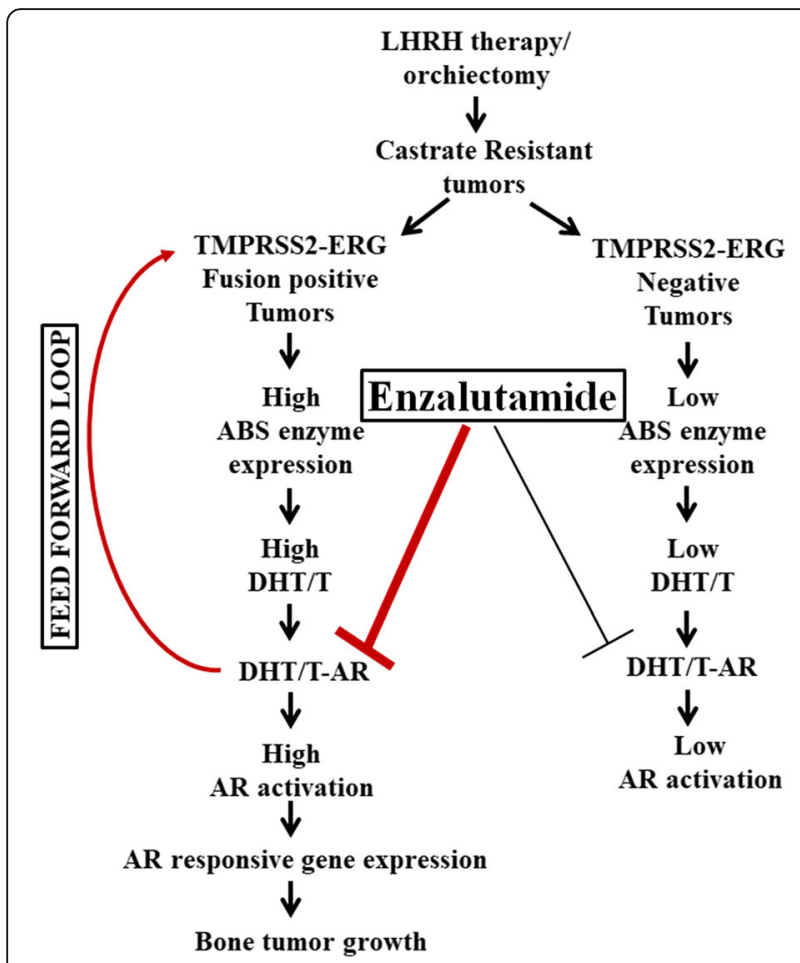

Fig. 5 Enzalutamide is more potent in inhibiting the bone tumor growth of ERG expressing tumor cells

AKR1C3 is an aldo-keto reductase, which uses androstendione and androstanedione for testosterone and DHT production, respectively. Steroid receptor dehydrogenease 1, 2 converts testosterone to DHT as well as androstenedione to androstanedione, while previous study show that the for SRD1,2 enzymes androstendione is a preferred substrate over testosterone [31] thus overexpression of HSD3B1/2 and AKR1C3 in TMPRSS2-ERG fusion positive cells leads to production of DHT from adrenal androgens. Bone tumor analysis of these enzymes show that ERG knockdown tumors have lower expression, suggesting in vivo function of ERG in maintaining the enzyme expression in bone tumors. Enzalutamide treatment resulting in suppression of AKR1C3 and HSD3B1/2 in tumor cells leads to inhibition of bone tumor growth. Previous studies show that AKR1C3 has been upregulated in abiratarone resistant tumors [32, 33], suggesting that, in the AR responsive phase, androgen biosynthesis is inhibited but that, in resistance phase, tumor cells acquire the capacity to overexpress AKR1C3 enzyme. Further, treatment of abiraterone resistant tumors with AKR1C3 inhibitor indomethacin leads to inhibition of testosterone production in cells and in vivo tumor growth. Enzymatic function of AKR1C3 in maintaining DHT production in CRPC phase and overexpression of AKR1C3 upon anti-androgen therapy to restore the androgen production makes this enzyme a key component in the intracellular pathway operating in tumoral androgen biosynthesis. Furthermore transcriptional regulation by TMPRSS2-ERG in bone tumor growth reveals the reliance of bone tumor growth on intra-tumoral androgen synthesis.

HSD3B1 has been shown to be a predictive biomarker for developing the castration resistance phase of prostate cancer upon androgen ablation therapies. Genetic analysis reveals that $1245 \mathrm{C}$ germline variant encodes a gainof function mutant of HSD3B1 which resulted in increased DHT production in tumors leading to the development of a castration resistance phenotype, and patients expressing this germline variant are more prone to develop CRPC [34]. Li et al., recently reported that HSD3B enzyme metabolizes the abiraterone to a more potent compound Delta (4)-abiraterone (D4A) which can further inhibit androgen biosynthetic enzyme activities involved in tumoral DHT production [35]. Our study also suggests that in ERG positive tumors this enzyme is overexpressed through a transcriptional mechanism for maintaining intra-osseous tumoral DHT production for expansion of tumors.

\section{Conclusions}

Our data support the hypothesis that, in TMPRSS2-ERG fusion-positive cells, androgens are produced locally through transcriptional regulation of androgen biosynthetic enzymes. Thus, TMPRSS2-ERG fusions can serve as predictive biomarkers for patients undergoing for anti-AR therapies. Our in vivo data with bone tumor models demonstrating that enzalutamide can inhibit bone tumor growth and androgen biosynthetic enzyme expression in tumors, further suggest the effectiveness of anti-AR therapies for metastatic bone tumors.

\section{Abbreviations}

AKR1C3: Aldo-Keto Reductase Family 1 Member C3; AR: Androgen Receptor; ATCC: American Type Culture Collection; BSA: Bovine serum albumin; CCNA2: Cyclin A2; CDC20: Cell Division Cycle 20; CDK1: Cyclin Dependent Kinase 1; $\mathrm{CO}_{2}$ : Carbon Dioxide; CRPC: Castration-resistant prostate cancer; CYP17: Cytochrome P450 Family 17 Subfamily A Member 1;

DHEA: Dehydroepiandrosterone; DHT: Dihydrotestosterone; DMEM: Dulbecco's Modified Eagle Medium; ERG: ETS Transcription Factor; $G_{1}$ : Gap 1 phase; G2: Gap 2 phase; GAPDH: Glyceraldehyde-3-Phosphate Dehydrogenase; HEPES: (4-(2-hydroxyethyl)-1-piperazineethanesulfonic acid); HPLC: High Performance Liquid Chromatography; HRP: Horseradish peroxidase; HSD3B1: Hydroxy-Delta-5-Steroid Dehydrogenase, 3 Beta- And Steroid Delta-Isomerase 1; HSD3B2: Hydroxy-Delta-5-Steroid Dehydrogenase, 3 Beta- And Steroid Delta-Isomerase 2; M: Mitosis; mM: milliMolar; MS: Mass spectrometry; $\mathrm{NaF}$ : Sodium fluoride; $\mathrm{NaVO}_{3}$ : Sodium metavanadate; $\mathrm{NIH}$ : National Institutes of Health; PBS: Phosphate-buffered saline; PC: Prostate Cancer; PSA: Prostate-specific antigen; RIPA ${ }^{++}$: Radioimmunoprecipitation assay buffer with protease inhibitors; S: Synthesis phase; SCID: Severe combined immunodeficiency; Scr: Scramble; shRNA: short hairpin RNA; STR: Short Tandem Repeat; TBST: Tris-buffered saline, 0.1\% Tween 20; TMPRSS2: Transmembrane Serine Protease 2; UBE2C: Ubiquitin Conjugating Enzyme E2 C; VCaP: Human Prostate; derived from metastatic site epithelial tissue; xg: $g$-force at accelerating; $\mu \mathrm{g}$ : microgram

Acknowledgements

Authors thank Diego Sbrissa for reading manuscript. 


\section{Author's contributions}

LS performed all the experiments and prepared preliminary figures. NM participated in the animal experiment, performed castration surgery and reviewed article. MLC contributed to study conception and design, review of data and manuscript preparation. SRC lead the study, designed experiments, performed data analysis, prepared final figures and wrote manuscript. All authors read and approved the final manuscript.

\section{Funding}

The work was supported by NIH-NCl Grant CA151557 and a contract from Astellas Medical affairs. The funding agencies reviewed the study design and not involved in the collection, analysis and interpretation of data and in preparation of manuscript.

\section{Availability of data and materials}

The data sets generated and/or analyzed during the current study available from corresponding author on reasonable request. The majority of data generated from the study are included in this published article.

\section{Ethics approval}

Institutional Animal Care and Use Committee (IACUC) at Wayne State University reviewed and approved animal protocol which describes the experiments performed in the manuscript. WSU animal facility is in compliance with Public Health Services, Office of Laboratory Animal Welfare with an assurance \#A3310-01 (The assurance letter can be found at http:// research.wayne.edu/iacuc/regulatory-and-accreditation.php). WSU's animal facility also accredited from the "Association for the Assessment and Accreditation for Laboratory Animal Care International (AAALAC)" for 3 years with a notification date March 23, 2018.

\section{Consent for publication}

Not applicable.

\section{Competing interests}

The authors' declare that they have no competing interests.

\section{Author details}

'Department of Urology, Wayne State University School of Medicine, 9245 Scott Hall, 540 E. Canfield Avenue, Detroit, Ml 48201, USA. ${ }^{2}$ Department of Pathology, Wayne State University School of Medicine, Detroit, MI 48201, USA. ${ }^{3}$ Department of Oncology, Wayne State University School of Medicine, Detroit, MI 48201, USA.

Received: 28 November 2018 Accepted: 20 September 2019 Published online: 21 October 2019

\section{References}

1. Watson PA, Arora VK, Sawyers CL. Emerging mechanisms of resistance to androgen receptor inhibitors in prostate cancer. Nat Rev Cancer. 2015; 15(12):701-11.

2. Mohler JL, Gregory CW, Ford OH 3rd, Kim D, Weaver CM, Petrusz P, et al. The androgen axis in recurrent prostate cancer. Clin Cancer Res. 2004;10(2):440-8.

3. Geller J, Albert JD, Nachtsheim DA, Loza D. Comparison of prostatic cance tissue dihydrotestosterone levels at the time of relapse following orchiectomy or estrogen therapy. J Urol. 1984;132(4):693-6.

4. Nishiyama T, Hashimoto $Y$, Takahashi K. The influence of androgen deprivation therapy on dihydrotestosterone levels in the prostatic tissue of patients with prostate cancer. Clin Cancer Res. 2004;10(21):7121-6.

5. Stanbrough M, Bubley GJ, Ross K, Golub TR, Rubin MA, Penning TM, et al. Increased expression of genes converting adrenal androgens to testosterone in androgen-independent prostate cancer. Cancer Res. 2006; 66(5):2815-25.

6. Montgomery RB, Mostaghel EA, Vessella R, Hess DL, Kalhorn TF, Higano CS et al. Maintenance of intratumoral androgens in metastatic prostate cancer: a mechanism for castration-resistant tumor growth. Cancer Res. 2008;68(11): 4447-54.

7. Mohler JL, Titus MA, Bai S, Kennerley BJ, Lih FB, Tomer KB, et al. Activation of the androgen receptor by intratumoral bioconversion of androstanedio to dihydrotestosterone in prostate cancer. Cancer Res. 2011;71(4):1486-96.
8. Ishizaki F, Nishiyama T, Kawasaki T, Miyashiro Y, Hara N, Takizawa I, et al. Androgen deprivation promotes intratumoral synthesis of dihydrotestosterone from androgen metabolites in prostate cancer. Sci Rep. 2013;3:1528.

9. Chang KH, Li R, Kuri B, Lotan Y, Roehrborn CG, Liu J, et al. A gain-of-function mutation in DHT synthesis in castration-resistant prostate cancer. Cell. 2013; 154(5):1074-84

10. Cai C, Chen S, Ng P, Bubley GJ, Nelson PS, Mostaghel EA, et al. Intratumoral de novo steroid synthesis activates androgen receptor in castration-resistant prostate cancer and is upregulated by treatment with CYP17A1 inhibitors. Cancer Res. 2011;71(20):6503-13.

11. Powell K, Semaan L, Conley-LaComb MK, Asangani I, Wu YM, Ginsburg KB, et al. ERG/AKR1C3/AR constitutes a feed-forward loop for AR signaling in prostate cancer cells. Clin Cancer Res. 2015;21(11):2569-79.

12. Demichelis F, Fall K, Perner S, Andren O, Schmidt F, Setlur SR, et al. TMPRSS2:ERG gene fusion associated with lethal prostate cancer in a watchful waiting cohort. Oncogene. 2007;26(31):4596-9.

13. Wang J, Cai Y, Ren C, Ittmann M. Expression of variant TMPRSS2/ERG fusion messenger RNAs is associated with aggressive prostate cancer. Cancer Res. 2006:66(17):8347-51.

14. Wang J, Cai Y, Yu W, Ren C, Spencer DM, Ittmann M. Pleiotropic biological activities of alternatively spliced TMPRSS2/ERG fusion gene transcripts. Cancer Res. 2008;68(20):8516-24.

15. Tomlins SA, Laxman B, Varambally $\mathrm{S}, \mathrm{Cao} X, \mathrm{Yu}$ J, Helgeson BE, et al. Role of the TMPRSS2-ERG gene fusion in prostate cancer. Neoplasia. 2008;10(2):177-88.

16. Yu J, Mani RS, Cao Q, Brenner CJ, Cao X, Wang X, et al. An integrated network of androgen receptor, polycomb, and TMPRSS2-ERG gene fusions in prostate cancer progression. Cancer Cell. 2010;17(5):443-54.

17. Zong Y, Xin L, Goldstein AS, Lawson DA, Teitell MA, Witte ON. ETS family transcription factors collaborate with alternative signaling pathways to induce carcinoma from adult murine prostate cells. Proc Natl Acad Sci U S A. 2009;106(30):12465-70.

18. Cai C, Wang H, Xu Y, Chen S, Balk SP. Reactivation of androgen receptorregulated TMPRSS2:ERG gene expression in castration-resistant prostate cancer. Cancer Res. 2009;69(15):6027-32.

19. Wang Q, Li W, Zhang Y, Yuan X, Xu K, Yu J, et al. Androgen receptor regulates a distinct transcription program in androgen-independent prostate cancer. Cell. 2009;138(2):245-56.

20. Attard G, Swennenhuis JF, Olmos D, Reid AH, Vickers E, A'Hern R, et al. Characterization of ERG, AR and PTEN gene status in circulating tumor cells from patients with castration-resistant prostate cancer. Cancer Res. 2009; 69(7):2912-8.

21. Crnalic S, Hornberg E, Wikstrom P, Lerner UH, Tieva A, Svensson O, et al. Nuclear androgen receptor staining in bone metastases is related to a poor outcome in prostate cancer patients. Endocr Relat Cancer. 2010;17(4):885-95.

22. Hornberg E, Ylitalo EB, Crnalic S, Antti H, Stattin P, Widmark A, et al. Expression of androgen receptor splice variants in prostate cancer bone metastases is associated with castration-resistance and short survival. PLoS One. 2011;6(4):e19059.

23. Zhang X, Morrissey C, Sun S, Ketchandji M, Nelson PS, True LD, et al. Androgen receptor variants occur frequently in castration resistant prostate cancer metastases. PLoS One. 2011;6(11):e27970.

24. Russell PK, Clarke MV, Skinner JP, Pang TP, Zajac JD, Davey RA. Identification of gene pathways altered by deletion of the androgen receptor specifically in mineralizing osteoblasts and osteocytes in mice. J Mol Endocrinol. 2012; 49(1):1-10.

25. Wiren KM, Zhang XW, Olson DA, Turner RT, Iwaniec UT. Androgen prevents hypogonadal bone loss via inhibition of resorption mediated by mature osteoblasts/osteocytes. Bone. 2012;51(5):83546.

26. Vanderschueren D, Vandenput L, Boonen S, Lindberg MK, Bouillon R, Ohlsson C. Androgens and bone. Endocr Rev. 2004:25(3):389-425.

27. Efstathiou E, Titus M, Tsavachidou D, Tzelepi V, Wen S, Hoang A, et al. Effects of abiraterone acetate on androgen signaling in castrate-resistant prostate cancer in bone. J Clin Oncol. 2012;30(6):637-43.

28. Guerrero J, Alfaro IE, Gomez F, Protter AA, Bernales S. Enzalutamide, an androgen receptor signaling inhibitor, induces tumor regression in a mouse model of castration-resistant prostate cancer. Prostate. 2013;73(12):1291-305.

29. Fizazi K, Scher HI, Miller K, Basch E, Sternberg CN, Cella D, et al. Effect of enzalutamide on time to first skeletal-related event, pain, and quality of life in men with castration-resistant prostate cancer: results from the randomised, phase 3 AFFIRM trial. Lancet Oncol. 2014;15(10):1147-56. 
30. Loriot Y, Miller K, Sternberg CN, Fizazi K, De Bono JS, Chowdhury S, et al. Effect of enzalutamide on health-related quality of life, pain, and skeletalrelated events in asymptomatic and minimally symptomatic, chemotherapynaive patients with metastatic castration-resistant prostate cancer (PREVAIL): results from a randomised, phase 3 trial. Lancet Oncol. 2015;16(5):509-21.

31. Chang KH, Li R, Papari-Zareei M, Watumull L, Zhao YD, Auchus RJ, et al. Dihydrotestosterone synthesis bypasses testosterone to drive castrationresistant prostate cancer. Proc Natl Acad Sci U S A. 2011;108(33):13728-33.

32. Sbrissa D, Semaan L, Govindarajan B, Li Y, Caruthers NJ, Stemmer PM, et al. A novel cross-talk between CXCR4 and PI4KIlla in prostate cancer cells. Oncogene. 2018

33. Liu C, Armstrong CM, Lou W, Lombard A, Evans CP, Gao AC. Inhibition of AKR1C3 activation overcomes resistance to Abiraterone in advanced prostate cancer. Mol Cancer Ther. 2017;16(1):35-44.

34. Beltran H, Prandi D, Mosquera JM, Benelli M, Puca L, Cyrta J, et al. Divergent clonal evolution of castration-resistant neuroendocrine prostate cancer. Nat Med. 2016;22(3):298-305.

35. Li Z, Bishop AC, Alyamani M, Garcia JA, Dreicer R, Bunch D, et al. Conversion of abiraterone to D4A drives anti-tumour activity in prostate cancer. Nature. 2015;523(7560):347-51.

\section{Publisher's Note}

Springer Nature remains neutral with regard to jurisdictional claims in published maps and institutional affiliations.

Ready to submit your research? Choose BMC and benefit from:

- fast, convenient online submission

- thorough peer review by experienced researchers in your field

- rapid publication on acceptance

- support for research data, including large and complex data types

- gold Open Access which fosters wider collaboration and increased citations

- maximum visibility for your research: over $100 \mathrm{M}$ website views per year

At BMC, research is always in progress.

Learn more biomedcentral.com/submissions 